\title{
How holobionts get sick-toward a unifying scheme of disease
}

\author{
Silvio D. Pitlik ${ }^{1^{*}}$ and Omry Koren ${ }^{2^{*}}$ (1)
}

\begin{abstract}
All humans, animals, and plants are holobionts. Holobionts comprise the host and a myriad of interacting microorganisms - the microbiota. The hologenome encompasses the genome of the host plus the composite of all microbial genomes (the microbiome). In health, there is a fine-tuned and resilient equilibrium within the members of the microbiota and between them and the host. This relative stability is maintained by a high level of microbial diversity, a delicate bio-geographic distribution of microorganisms, and a sophisticated and intricate molecular crosstalk among the multiple components of the holobiont. Pathobionts are temporarily benign microbes with the potential, under modified ecosystem conditions, to become key players in disease. Pathobionts may be endogenous, living for prolonged periods of time inside or on the host, or exogenous, invading the host during opportunistic situations. In both cases, the end result is the transformation of the beneficial microbiome into a health-perturbing pathobiome. We hypothesize that probably all diseases of holobionts, acute or chronic, infectious or non-infectious, and regional or systemic, are characterized by a perturbation of the healthy microbiome into a diseased pathobiome.
\end{abstract}

Keywords: Microbiome, Disease, Pathobiome, Pathobiont, Microbiota

\section{One sentence summary}

We hypothesize that probably every illness of holobionts is characterized by some perturbation of the microbiome/microbiota into a pathobiome.

\section{Main text}

For more than a century, diseases of humans have been classified in a dichotomous fashion as infectious and non-infectious. In the former group, causality has been framed in the context of Koch's postulates, in most cases linking a single microbe with a single disease. This approach, although incomplete from a patho-physiological point of view, has led to enormous advances in the prevention and treatment of infectious diseases. During the last decade, a huge amount of data has been gathered on the composition of the human microbiota in health and disease. Nowadays, almost no sickness has been overlooked by this trend, and there is expanding information on the complex configuration of the human microbiota in

\footnotetext{
*Correspondence: pitlik@post.tau.ac.il; omry.koren@biu.ac.il

${ }^{1}$ Department of Molecular Genetics, Weizmann Institute of Science, Rehovot, Israel

${ }^{2}$ Faculty of Medicine, Bar Ilan University, Safed, Israel
}

almost every illness. Interestingly, this knowledge includes not only non-infectious chronic diseases such as obesity, diabetes mellitus, inflammatory bowel disease, and many others but also a growing list of infectious diseases that were traditionally ascribed to a single pathogen behaving as a lone warrior against the host. For example, in AIDS, a disease caused by the HIV virus, a perturbed microbiota is found in the vagina of women with a higher predisposition to contract the infection [1], in the gut of patients already infected with HIV [2], and also in HIV-negative neonates born to mothers who received successful anti-retroviral therapy [3]. As an additional example, Staphylococcus aureus lives as a dormant pathobiont in the nares of more than a third of healthy individuals. Recent investigations have shown that this bacterium remains confined to the nares due to an intricate interaction with other organisms. For example, the nearby presence of Staphylococcus lugdunensis kills S. aureus through a newly discovered antibiotic termed lugdunin [4]. On the other hand, the adjacent growth of Corynebacterium striatum and $S$. aureus results in diminished expression of virulence genes of $S$. aureus but augmented expression of genes involved in non-virulent 
colonization [5]. Switching roles from defenders to attackers, S. lugdunensis or C. striatum may cause serious infections [6, 7]. S. aureus cohabitating other body sites, for example, the lungs, may increase the virulence of other microbes in the vicinity [8]. Escherichia coli, a major member of the gut microbiota, may cause life-threatening infections. Conversely, probiotic strains of the same bacterium may prevent recurrence of bladder infections in women [9] or the development of rampant cholera infection in experimental settings [10]. Many other microbes, acting as endogenous or exogenous pathobionts, may appear to act as independent aggressors, but their ability to trigger disease is actually orchestrated and regulated by members of the microbiome/microbiota. For example, carriage of the arbovirus is influenced by the microbiota of its mosquito vector [11] and attraction of biting mosquitoes is dependent on the individual's skin microbiota [12].

We are still in a difficult position to optimally define a "normal" or "healthy" microbiota. As in ecological niches, there are multiple states of equilibrium corresponding to healthy states. For example, some of the biomarkers for dysbiosis include an increase in beta (between sample) diversity, a decrease in alpha (within sample) diversity, an increase in the abundance of members of Proteobacteria and opportunistic pathobionts, and an increase in inflammatory markers. As summarized in Fig. 1a, these changes happen not only in obese individuals ("bad" or "diseased" microbiome) but also in women in their third trimester ("good" or "healthy" microbiome) [13, 14].

Interestingly, an adverse outcome of influenza and a suboptimal immunogenicity of the flu vaccine are influenced by these conditions, in humans and experimental animals (Fig. 1) [15-18]. Similar interactions between pathobionts, the microbiota, and the host are increasingly being described in animals and plants [19-21]. In sick corals, there is a significant change in the ranking order of viruses that are also present in healthy specimens but with a distinct load for each type of virus [22].

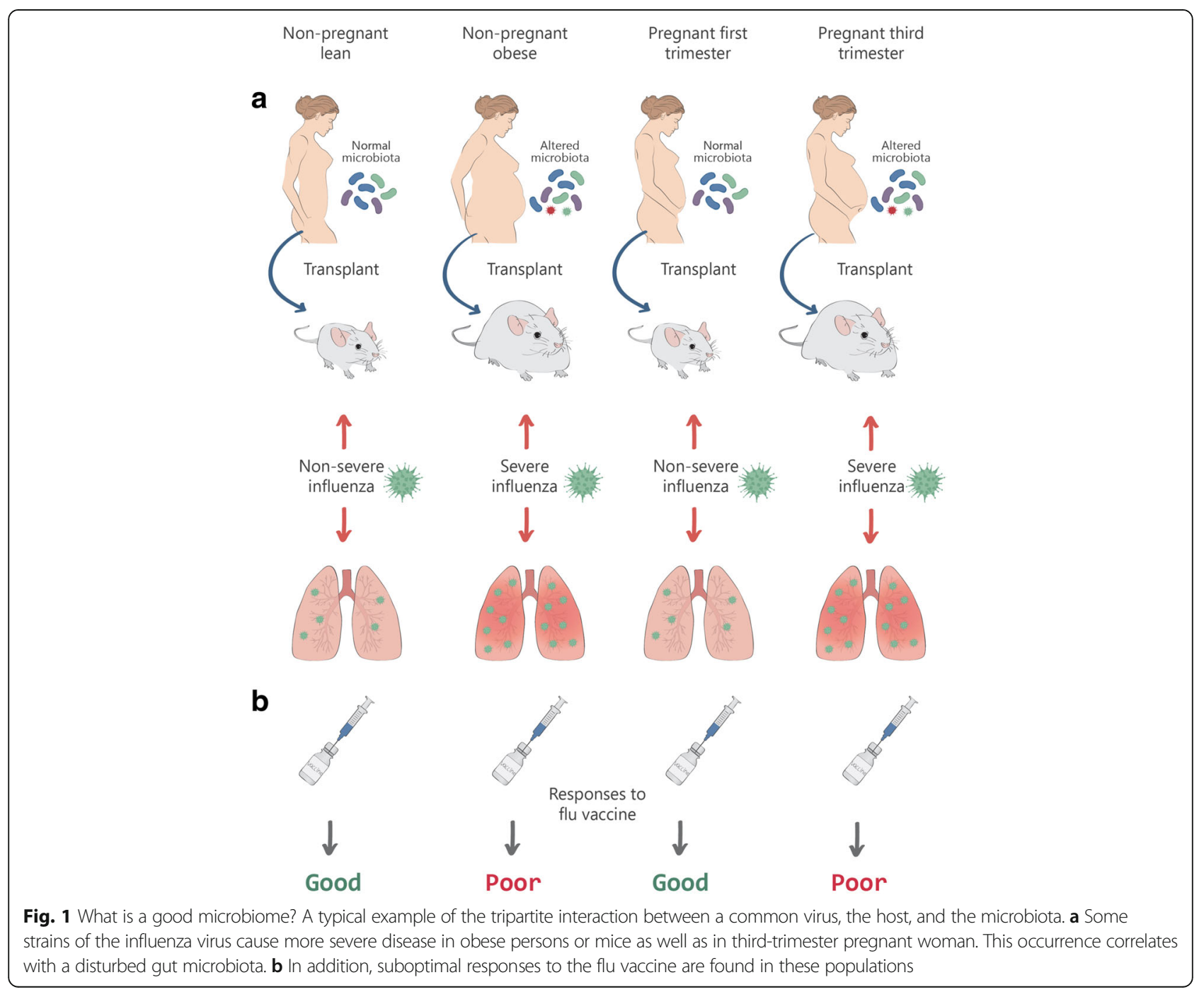


In light of this paradigm, we suggest that novel ways to establish complex causation, as opposed to associations between a perturbed microbiota and a sick host, should be developed. Under this scheme, elucidation of causality becomes a very difficult task which can be compared metaphorically to untying a Gordian knot. Alternatively, we can apply an ecological approach and recognize that disease affects not the host but the holobiont in all its complexity. When doing research on the microbiota, we are actually dealing with an intricate system composed by microbial individuals interacting in a social fashion. Consequently, when trying to understand holobionts in health and disease, we may apply novel methods developed by social and economic scientists [23]. Relatively simplified biomarkers for selected diseases may be looked for and calculated by complex computational methods based on parameters such as microbial diversity of the microbiota, predominance or absence of specific species of bacteria, levels of defined metabolites, and other.

Words have an extraordinary power [24]. Some (like pathogen or pathogenicity) may obscure the right interpretation of biological processes, and other words may facilitate the clarification of complex developments [25]. We claim that the introduction of certain terms to the world of Medicine may greatly improve our understanding of both health and disease. These words include holobionts, pathobionts, and pathobiome (a disturbed or dysbiotic microbiome).

The current classification of diseases into infectious and non-infectious should be revised. While there may be one or more pathobionts playing a central role in the former case, there is a concurrent perturbation of the microbiota which can either precede or follow the introduction of the pathobiont/s into the holobiont system. The diagnosis of classic infectious diseases is performed by well-established methods including microscopic observation of a specific microbe, culture-dependent and culture-independent molecular techniques such as PCR, or the detection of specific antibodies as a result of an active infection. Still, under this approach, important questions remain unanswered. For example, one might ask why certain hosts develop disease, while others remain healthy. In contrast, dysbiotic or perturbed states of the microbiota are not routinely evaluated in clinical practice due to their complexity and the scarcity of simple ways to characterize them. The multiplicity of co-factors and the slow progression of their effects on holobionts complicate the elucidation of the pathogenesis of many metabolic, inflammatory, degenerative, neoplastic, and even psychiatric diseases. The interaction between specific genetic mutations, the microbiota, and environmental factors have been extensively studied in certain diseases such as Crohn's disease, both in humans and animal models [26]. In contrast, the characteristics of the microbiota remain still unexplored in individuals with certain common genetic conditions such as Tay-Sachs, thalassemia, neurofibromatosis, and Jackson-Weiss syndrome. In other examples, such as cystic fibrosis [27], Huntington disease [28], severe combined immunodeficiency disorder [29], and sickle cell disease [30], a growing body of information is emerging on associated disturbances of the microbiota. The currently consolidating idea that interactive co-evolution of the host with its microbiota is an important driving force for evolution may predict future elucidations in the mechanisms of a holobiont becoming sick [31]. In recent years, the major roles played by environmental factors in the development of these diseases of holobionts have begun to be deciphered. Among others, these factors include overuse of antibiotics-especially at critical periods of life-cesarean sections, avoidance of breast feeding, unhealthy diets, and exposure to toxic substances. The proposed paradigm has the potential to develop novel preventive and therapeutic approaches. We suggest applying a strong ecologic attitude toward the preservation of health in all holobionts on Earth.

\section{Acknowledgements \\ OK is supported by research grants from the Israeli Science Foundation, Minerva ARCHES, the Marie Curie Career integration grant and from the Canadian-Israel Health Initiative, jointly funded by the Canadian Institutes of Health Research, the Israel Science Foundation, the International Develop- ment Research Centre, Canada and the Azrieli Foundation.}

\section{Funding}

Not applicable.

Availability of data and materials

Not applicable.

Authors' contributions

SDP and OK wrote the manuscript. Both authors read and approved the final manuscript.

Competing interests

The authors declare that they have no competing interests.

Consent for publication

Not applicable.

Ethics approval and consent to participate Not applicable.

\section{Publisher's Note}

Springer Nature remains neutral with regard to jurisdictional claims in published maps and institutional affiliations.

Received: 31 March 2017 Accepted: 4 June 2017

Published online: 24 June 2017

References

1. Cohen J. Infectious disease. Vaginal microbiome affects HIV risk. Science. 2016;353(6297):331. 
2. Liu J, Williams B, Frank D, Dillon SM, Wilson CC, Landay AL. Inside out: HIV, the gut microbiome, and the mucosal immune system. J Immunol. 2017; 198(2):605-14.

3. Bender JM, Li F, Martelly S, Byrt E, Rouzier V, Leo M, Tobin N, Pannaraj PS, Adisetiyo H, Rollie A, et al. Maternal HIV infection influences the microbiome of HIV-uninfected infants. Sci Transl Med. 2016;8(349):349ra100.

4. Zipperer A, Konnerth MC, Laux C, Berscheid A, Janek D, Weidenmaier C, Burian M, Schilling NA, Slavetinsky C, Marschal M, et al. Human commensals producing a novel antibiotic impair pathogen colonization. Nature. 2016; 535(7613):511-6.

5. Ramsey MM, Freire MO, Gabrilska RA, Rumbaugh KP, Lemon KP. Staphylococcus aureus shifts toward commensalism in response to Corynebacterium species. Front Microbiol. 2016;7:1230.

6. Kimura SI, Gomyo A, Hayakawa J, Akahoshi Y, Harada N, Ugai T, Komiya Y, Kameda K, Wada H, Ishihara Y, et al. Clinical characteristics and predictive factors for mortality in Coryneform bacteria bloodstream infection in hematological patients. J Infect Chemother. 2016;23(3):148-53.

7. Lin JF, Cheng CW, Kuo AJ, Liu TP, Yang CC, Huang CT, Lee MH, Lu JJ. Clinical experience and microbiologic characteristics of invasive Staphylococcus lugdunensis infection in a tertiary center in northern Taiwan. J Microbiol Immunol Infect. 2015;48(4):406-12.

8. Cohen TS, Hilliard JJ, Jones-Nelson O, Keller AE, O'Day T, Tkaczyk C, DiGiandomenico A, Hamilton M, Pelletier M, Wang Q, et al. Staphylococcus aureus alpha toxin potentiates opportunistic bacterial lung infections. Sci Transl Med. 2016;8(329):329ra331.

9. Wullt B, Svanborg C. Deliberate establishment of asymptomatic bacteriuria-a novel strategy to prevent recurrent UTI. Pathog. 2016;5(3)

10. Sengupta C, Ekka M, Arora S, Dhaware PD, Chowdhury R, Raychaudhuri S. Cross feeding of glucose metabolism byproducts of Escherichia coli human gut isolates and probiotic strains affect survival of Vibrio cholerae. Gut Pathog. 2017;9:3.

11. Hegde S, Rasgon JL, Hughes GL. The microbiome modulates arbovirus transmission in mosquitoes. Curr Opin Virol. 2015;15:97-102.

12. Verhulst NO, Takken W, Dicke M, Schraa G, Smallegange RC. Chemical ecology of interactions between human skin microbiota and mosquitoes. FEMS Microbiol Ecol. 2010;74(1):1-9.

13. Koren O, Goodrich JK, Cullender TC, Spor A, Laitinen K, Backhed HK, Gonzalez A, Werner JJ, Angenent LT, Knight R, et al. Host remodeling of the gut microbiome and metabolic changes during pregnancy. Cell. 2012; 150(3):470-80.

14. Ridaura VK, Faith JJ, Rey FE, Cheng J, Duncan AE, Kau AL, Griffin NW, Lombard V, Henrissat B, Bain JR, et al. Gut microbiota from twins discordant for obesity modulate metabolism in mice. Science. 2013;341(6150):1241214.

15. Ghedin E, Schultz-Cherry S. Host response: pregnancy impairs flu defences. Nat Microbiol. 2017;2:17077.

16. Cho WJ, Lee DK, Lee SY, Sohn SH, Park HL, Park YW, Kim H, Nam JH. Diet-induced obesity reduces the production of influenza vaccineinduced antibodies via impaired macrophage function. Acta Virol. 2016; 60(3):298-306.

17. Park HL, Shim SH, Lee EY, Cho W, Park S, Jeon HJ, Ahn SY, Kim H, Nam JH. Obesity-induced chronic inflammation is associated with the reduced efficacy of influenza vaccine. Hum Vaccin Immunother. 2014;10(5):1181-6.

18. Kosaraju R, Guesdon W, Crouch MJ, Teague HL, Sullivan EM, Karlsson EA, Schultz-Cherry S, Gowdy K, Bridges LC, Reese LR, et al. B cell activity is impaired in human and mouse obesity and is responsive to an essential fatty acid upon murine influenza infection. J Immunol. 2017.

19. Jakuschkin B, Fievet V, Schwaller L, Fort T, Robin C, Vacher C. Deciphering the pathobiome: intra- and interkingdom interactions involving the pathogen Erysiphe alphitoides. Microb Ecol. 2016;72(4):870-80.

20. Bahrndorff S, Alemu T, Alemneh T, Lund Nielsen J. The microbiome of animals: implications for conservation biology. Int J Genomics. 2016;2016: 5304028.

21. Rosenberg E, Koren O, Reshef L, Efrony R, Zilber-Rosenberg I. The role of microorganisms in coral health, disease and evolution. Nat Rev Microbiol. 2007:5(5):355-62.

22. Thurber RV, Payet JP, Thurber AR, Correa AM. Virus-host interactions and their roles in coral reef health and disease. Nat Rev Microbiol. 2017.

23. Hofman JM, Sharma A, Watts DJ. Prediction and explanation in social systems. Science. 2017;355(6324):486-8.

24. Mendelson M, Balasegaram M, Jinks T, Pulcini C, Sharland M. Antibiotic resistance has a language problem. Nature. 2017;545(7652):23-5.
25. Casadevall A, Pirofski LA. Microbiology: ditch the term pathogen. Nature. 2014;516(7530):165-6.

26. Balasubramanian I, Gao N. From sensing to shaping microbiota: insights into the role of NOD2 in intestinal homeostasis and progression of Crohn's disease. Am J Physiol Gastrointest Liver Physiol. 2017. doi: 10.1152/ajpgi. 00330.02016.

27. Hoppe JE, Zemanick ET. Lessons from the lower airway microbiome in early CF. Thorax. 2017.

28. Tremlett H, Bauer KC, Appel-Cresswell S, Finlay BB, Waubant E. The gut microbiome in human neurological disease: a review. Ann Neurol. 2017; 81(3):369-82.

29. Lane JP, Stewart CJ, Cummings SP, Gennery AR. Gut microbiome variations during hematopoietic stem cell transplant in severe combined immunodeficiency. J Allergy Clin Immunol. 2015;135(6):1654-6.

30. Zhang D, Chen G, Manwani D, Mortha A, Xu C, Faith JJ, Burk RD, Kunisaki Y, Jang JE, Scheiermann C, et al. Neutrophil ageing is regulated by the microbiome. Nature. 2015;525(7570):528-32.

31. Rosenberg E, Zilber-Rosenberg I. Microbes drive evolution of animals and plants: the hologenome concept. MBio. 2016;7(2):e01395.

\section{Submit your next manuscript to BioMed Central and we will help you at every step:}

- We accept pre-submission inquiries

- Our selector tool helps you to find the most relevant journal

- We provide round the clock customer support

- Convenient online submission

- Thorough peer review

- Inclusion in PubMed and all major indexing services

- Maximum visibility for your research

Submit your manuscript at www.biomedcentral.com/submit
Biomed Central 